\title{
LA LÍRICA ROMÁNTICA, POLÍTICA Y RELIGIOSA DEL NIETZSCHE INFANTIL EN NAUMBURGO AL COMIENZO DE SU “TERCER PERIODO”
}

\author{
Victor Muriel Martín \\ Albert-Ludwigs-Universität Freiburg \\ Friburgo, Alemania \\ vmurielm@gmail.com
}

RESUMEN / ABSTRACT

Este estudio se centra en la lírica de Friedrich Nietzsche en Naumburgo, utilizando como modelo una selección de poemas correspondientes a la antología que regala a su madre en 1858, la cual, a ojos del Nietzsche infantil, abría su "tercer periodo" de creación poética. El presente análisis girará sobre tres ejes fundamentales: lírica religiosa, lírica romántica de la naturaleza y lírica política. El objetivo será mostrar los conflictos, la pluralidad de voces y las fuentes más importantes que resuenan en esta antología, sirviendo además como hilo conductor para obtener una visión general de las tentativas poéticas del Nietzsche previo a sus inicios como alumnus portensis.

Palabras clave: Friedrich Nietzsche, Nietzsche infantil, romanticismo, religiosidad, poesía política.

THE YOUNG NIETZSCHE'S ROMANTIC, POLITIC, AND RELIGIOUS POETRY IN NAUMBURG AT THE BEGINNING OF HIS “THIRD PERIOD”

This paper examines Friedrich Nietzsche's poetry in Naumburg, analyzing a selection of poems from an anthology that he wrote as a child and gave to his mother in 1858. In the eyes of the young Nietzsche, this anthology opened his "third period" of poetic creation. The analysis focuses on three key aspects: religious poetry, romantic and nature poetry, and politic poetry. The aim of this study is to show the conflicts, the plurality of voices and the main sources that resonate in this anthology, which is also used to get an overview of Nietzsche's poetry attempts before his start as an alumnus portensis. 
KEYWORDS: Friedrich Nietzsche, Young Nietzsche, romanticism, religiosity, political poetry.

\section{ASPECTOS GENERALES: EL NIETZSCHE INFANTIL COMO POETA Y EL CONTEXTO FAMILIAR}

A pesar de la relevancia que ha cobrado la figura de Nietzsche como una de las tentativas más importantes en los últimos siglos de superar las rígidas fronteras entre literatura, poesía y filosofía, tal y como la tradición las clasificaba y distinguía, la investigación rigurosa de la lírica nietzscheana ha sufrido un cierto abandono por parte de la recepción de su obra, si lo comparamos con la intensidad con que han sido estudiados sus escritos aforísticos o tratados. Esta carencia en la investigación contrasta, no obstante, con las aproximadamente setecientas composiciones líricas que se han conservado, si bien la mayoría son de carácter póstumo (Grätz y Kaufmann 3). La única obra poética en sentido estricto que Nietzsche publica en vida será el ciclo poético Idyllen aus Messina, que sale a la luz en 1882 en la Internationale Monatsschrift. De los ocho poemas que componen este ciclo, seis serán de nuevo publicados con algunos cambios en la segunda edición de Die Fröhliche Wissenschaft, en 1887. A finales de 1888, Nietzsche tiene ya finalizados y preparados los Dionysos-Dithyramben, para los cuales se valió de una serie de poemas pertenecientes al periodo de la cuarta parte de Also sprach Zarathustra, la cual no había sido impresa más que de modo privado para un reducido número de personas. La publicación de los Dionysos-Dithyramben no pudo, sin embargo, concluirla a causa del repentino colapso mental que sufrió a comienzos de 1889 en Turín.

No obstante, la fecundidad poética de Nietzsche no es un fenómeno exclusivo de sus escritos tardíos, sino que atraviesa toda su vida. Autores como Ziemann han resaltado cómo las más tempranas tentativas literarias de Nietzsche que se conservan son poemas, así como su última obra concluida es también un ciclo poético (Ottmann 150). Esta prolificidad lírica llama la atención por lo temprano de tales tentativas, siendo sorprendente que el primer poema conservado lo haya escrito a los ocho años (Nietzsche, $K G W$ I/1 318). Sin duda, existe en torno a la figura de Nietzsche una gran cantidad de textos y material de épocas muy tempranas que raramente se conserva en otros pensadores, incluso a pesar de su fuerte tendencia a destruir y quemar 
sus más tempranas producciones, como advierte su hermana Elisabeth (Nietzsche, Gedichte 11).

Rescatar críticamente sus poemas de infancia resulta especialmente cautivador, pues sirve como un nutricio material biográfico-histórico que permite vislumbrar los intereses del joven Nietzsche. Esto abre a una experiencia más enriquecedora de sus escritos tardíos, al evidenciar desde sus primeros años el carácter multifacético y apasionado de su personalidad. Además, como se verá, tiene un añadido interés social e histórico general, pues a través de ellos podemos acercarnos a las vivencias de una época, a la convulsa Prusia de mitad del siglo XIX, casi tres décadas antes de la formación del Imperio alemán, a su cosmovisión y creencias y al modo en que los jóvenes crecidos en ambientes conservadores se impregnaban de las prácticas religiosas y de las corrientes artísticas en las instituciones educativas y familiares.

Cabe advertir que este carácter multifacético no se agota en la producción lírica. Paralelamente a esta, es destacable su creación literaria y musical. Únicamente en el año de la presente antología, Nietzsche elabora diversas composiciones para piano, como Allegro moderato, Allegro con brio o Maestoso adagio, entre otros. Además, destacará un boceto para la escritura de un drama, Untergang Trojas, cuyos protagonistas serán los dioses griegos; así como su primera tentativa autobiográfica, Aus meinem Leben (cit. en Schlechta 16). El Nietzsche infantil tenía, además, una especial sensibilidad por la pintura. El primer tomo de sus escritos infantiles, recogido en la Kritische Gesamtausgabe $^{1}(K G W I / 1)$-editado en 1995 por Johann Figl, en la editorial Walter de Gruyter-que recoge apuntes y notas póstumas entre 1854 a 1858 - es decir, entre los diez y los catorce años de edad de Nietzsche- y contiene numerosos bocetos, dibujos y diversos "planos militares" que, a modo de juego, diseñaba con su hermana y sus amigos. Asimismo, Nietzsche ofrecía frecuentemente regalos a familiares, como el dibujo de la tumba de su padre con una corona de flores que, en 1855 , entregó presumiblemente a su abuela y al que refiere la madre de Nietzsche en su correspondencia privada (Figl 33).

En el presente artículo se utilizarán para las citas correspondientes a las obras póstumas o publicadas de Nietzsche la edición de las obras completas en alemán de la Kritische Gesamtausgabe, editada por Figl o Colli y Montinari, utilizando para ello las siglas KGW e indicando a continuación el tomo correspondiente. Para su correspondencia privada se utilizará la edición de las Sämtliche Briefe. Kritische Studienausgabe en ocho tomos indicada bajo la abreviatura KGB junto al volumen concreto. 
La naturaleza de gran parte de los poemas conservados en sus primeros años en Naumburgo consiste en tareas y ejercicios para la escuela, o bien en regalos a su madre. La selección de poemas que servirá como base para el presente artículo pertenece a este segundo grupo: se trata de una antología de diez poemas que Nietzsche, aún con trece años, regala a su madre por su trigésimo segundo cumpleaños, el 2 de febrero de 1858, en los últimos meses de su infancia en el Domgymnasium de Naumburgo. Aquí permanecerá hasta verano del mismo año, meses antes de recibir el cinco de octubre la admisión a la prestigiosa escuela Pforta y a la cual dedica en esta antología un poema titulado "Nach Pforta", siendo a su vez el primer testimonio escrito donde aparece el nombre de la escuela. Si bien la admisión oficial a Pforta la recibirá unos meses más adelante, Nietzsche tuvo siempre, tal y como escribirá en 1861, una especial inclinación por la prestigiosa escuela donde pasaron grandes personalidades como Fichte, Ranke o Klopstock. La particularidad de esta antología, en la que predomina la forma lírica de las Lieder - poemas que deben ser leídos en voz alta con la musicalidad propia de una canción-, es que con ella comienza a ojos de Nietzsche lo que ya por aquella época consideraba el "tercer periodo" de su creación poética infantil, comenzando a cobrar una relevancia especial respecto a las tentativas líricas de años anteriores. Así lo escribirá meses después en su primera autobiografía de 1858 (Nietzsche $K G W I / 1307$ ).

En la familia Nietzsche, las celebraciones de cumpleaños eran una tradición muy querida que constituía un importante rito familiar acompañado de diversas demostraciones artísticas. Figl muestra cómo el padre de Nietzsche, el pastor protestante Carl Ludwig Nietzsche, se empecinaba en escribir poemas de felicitaciones a la abuela Erdmuthe (22), algo que Nietzsche comenzó a hacer al menos desde el año 1852, felicitando a su madre por el nuevo año, tal y como se conserva en los escritos póstumos (Nietzsche, $K G W, I / 1317$ 318). Tales fiestas eran un auténtico acontecimiento, siendo también habitual regalar pequeñas composiciones musicales o recitar versos y canciones. Tras la muerte del padre, estas celebraciones adquirieron paulatinamente un tono mortuorio, sirviendo continuamente como evocación de su figura (Figl 27). Un ejemplo paradigmático de esta tendencia en la presente antología es el poema "Wohin?", que da cierre a la antología y en el que predomina un tono melancólico y nostálgico, que finaliza con el ruiseñor llevando flores a la tumba de su padre en Röcken, destacando un sentimiento de soledad al final de cada estrofa desde los recursos al hogar (Heimathsort), a la casa y tumba paterna (Vaterhaus y Vatergrab). La figura del ruiseñor 
como elemento melancólico se encuentra presente en la literatura occidental desde la antigüedad, caracterizándose no solo por su bello canto, sino por ser una de las pocas aves que cantan hasta bien entrado el ocaso, vinculándose metafóricamente a la noche y siendo muy importante en poetas románticos como Joseph von Eichendorff, en sus poemas "Nachtigall" y "Nachtlied", o Heinrich Heine en poemas como "Im Anfang war die Nachtigall". En idiomas como el alemán, el sustantivo encierra incluso el término noche (Nacht-igall). En el Nietzsche infantil este recurso parece estar ligado a una experiencia existencial del devenir, tal y como anotará de nuevo al año siguiente, el 16 de agosto de 1859: "Schau ich in das Rosengewölk, schau ich auf die leis bewegten Rosen, höre ich die Nachtigallen die aus Lilienguirlanden bange Seupfer schallen lassen, so rufe ich schmerzlich sic transit gloria mundi!"2 (Nietzsche, $K G W I / 2110)$. Al elemento de la soledad que se refleja en su lírica infantil en Naumburgo, ocasionado por la experiencia de la muerte de su padre y de diversos familiares, se le añaden tras la muerte de aquel las dificultades del traslado de su familia de Röcken a Naumburgo, que ocasionaron, junto a su carácter serio y reservado, diversas dificultades para establecer relaciones con el resto de sus compañeros, tal y como escribe en su primera autobiografía. Sin embargo, la indiscutible experiencia creativa de la soledad se verá complejizada desde otros estados anímicos concomitantes, como pueden ser los sentimientos de integración familiar o el advenimiento de la amistad: pronto conoció a los que serían sus grandes amigos de infancia, Wilhelm Pinder y Gustav Krug (Nietzsche, $K G W, I / 1288$ ).

Sobre las fuentes fundamentales que inspiraban a Nietzsche en Naumburgo en el periodo previo a sus inicios como alumnus portensis, cabe destacar, en primer lugar, el papel destacado de las canciones misales, por ejemplo en los himnos protestantes de Gerhardt, y la Biblia de Lutero (Die Bibel oder die ganze Heilige Schrift des alten und neuen Testaments), de la cual Nietzsche poseía un ejemplar heredado de su padre en la edición de 1818 de la Cansteinische Bibelanstalt, y de la que hará uso impregnando sus versos de figuras y metáforas bíblicas o reproducciones más o menos transformadas de versículos determinados. Junto a la Biblia, ejercerán una influencia importante

\footnotetext{
"Cuando miro las nubes enrojecidas del atardecer, cuando miro las rosas que se mueven suavemente, cuando escucho los ruiseñores que de las guirnaldas de lirios emiten suspiros inquietantes, entonces clamo dolorosamente: jsic transit gloria mundi!' [Traducción propia].
} 
autores románticos como Eichendorff, Heine, Platen, Lenau, Novalis o Rückert. A estos, además, habrá de añadirse, como se verá, el importante papel de la lírica de Körner, a quien conocía ya en su época de Naumburgo, así como el poeta de lírica infantil Friedrich Güll. Por otro lado, es importante tener en cuenta la probabilidad de que en estos años aún no conozca a Hölderlin, si bien Hermann Schmidt defiende esta posibilidad, sosteniendo que le resulta evidente de modo intuitivo desde poemas anteriores, debido a semejanzas estilísticas y de contenido (777). Más adelante, ya en Pforta, la figura de Hölderlin será, sin embargo, fundamental en la lírica del Nietzsche juvenil, llegando a calificarlo a finales de 1861 como su poeta preferido (Liebligsdichter) (Nietszche, $K G W I / 2$ 338). Un papel esencial en las experiencias líricas del Nietzsche infantil lo jugará su abuelo, David Ernst Oehler, personaje de alta sensibilidad y carácter humanista, que abrirá a Nietzsche a diversos poetas, como Hölty, tal y como este anota retrospectivamente en 1875 recordando sus años de infancia: "Als der Großvater mir Hölty's "Wunderseliger Mann" erklärte"3 (Nietzsche, $K G W I V / 1$ 270). La influencia de Hölty en la lírica del Nietzsche infantil ha sido destacada por Figl, quien llama la atención especialmente sobre el modo en que ambos se relacionan con la tumba paterna en sus poemas, compartiendo elementos muy parecidos y recurriendo a la metáfora de pájaros cantores como el ruiseñor.

A continuación, se procederá a analizar las tendencias generales de la presente antología a través de la división entre una lírica religiosa, lírica política y lírica romántica de la naturaleza, las cuales servirán como hilo conductor para obtener una visión general de las inquietudes y el trasfondo de la poesía infantil y juvenil de Nietzsche atendiendo a su historia efectual.

\section{LÍRICA RELIGIOSA. RITOS E INFLUENCIAS DEL MILIEU LUTERANO Y COMIENZOS DE UNA TEOLOGÍA FILOSÓFICA}

En los escritos del Nietzsche infantil predomina un lenguaje altamente religioso, reflejando el modo tradicional y estandarizado en el que le fue enseñada la religiosidad: a través de sentencias bíblicas, rimas y rezos. Los valores y ritos luteranos le son transmitidos de un modo muy intenso tanto en el ambiente familiar como en la escuela, de tal modo que el sentido mismo 
de la realidad estaba atravesado por la creencia en Dios. La asiduidad con la que la familia Nietzsche asistía a misas y cánticos se refleja en la repetición continuada de misales protestantes en los versos de Nietzsche, llegando incluso a componer corales (Nietzsche, $K G W I / 1$ 195) y viviendo con una intensidad especial las Kirchenlieder no solo en el servicio religioso sino también en la vida privada. En este sentido, Figl advierte que la mayoría de las notas, cartas o composiciones artísticas de esta época remiten a la figura divina como guía, mostrando una dependencia absoluta del hombre de su inserción en la creación (28-29). Frente a las antologías de años anteriores -por ejemplo, la que compuso en 1856-, en la de 1858 se observa un uso mucho más elevado de conceptos y figuras cristianas como Dios, Señor, Padre o Jesús, o la dedicatoria temática a la Navidad en dos de los cinco poemas que conforman el ciclo poético Der Winter.

En primer lugar, destacan en la antología dos poemas previos al cierre, "Am Morgen" y "Am Abend", que consisten en oraciones o rezos que se llevaban a cabo al comienzo y al ocaso del día (Morgen- y Abendgebete), muy habituales en la praxis evangélica del contexto cultural protestante y más aún en las casas parroquiales protestantes en la Prusia de mediados del siglo XIX. En este ambiente evangélico, era común que los niños escribieran, memorizaran y recitaran poemas tanto para iniciar el día, a través de las denominadas Morgengebete, así como para finalizarlo mediante las Abendgebete. Estos poemas no solo eran muy cuidados en el ambiente doméstico de las familias influenciadas por el ambiente cultural del Biedermeier, sino que eran también trabajados en las escuelas, ejerciendo un importante papel en las prácticas pedagógicas, como puede observarse en los ejercicios que acompañan a los poemas a modo de tareas en diversos libros utilizados en las clases de alemán a mediados del siglo XIX. En el libro escolar Sprachübungen für deutsche Schulen. Erster Heft für die Unterklassen (1843), de Joseph Anton Geist, se reproducen fragmentos de la lírica de Friedrich Güll, poeta alemán protestante especializado en poemas infantiles compuestos para ser cantados (Kinderlieder). Entre los numerosos poemas se encuentra uno titulado del mismo modo que la Lied de Nietzsche, "Am Abend", acompañado de una anotación al final que exige como tarea copiarla y memorizarla (Geist 35). Nietzsche seguía estas prácticas pedagógicas en las clases de religión del Naumburger Domgymnasium, siendo habitual aprender de memoria numerosas sentencias y canciones bíblicas, tal y como se refleja a través de sus anotaciones en los cuadernos de escuela publicados póstumamente (Nietzsche, $K G W$ 
I/2 347). Ejemplo de ello podría ser la "Osterlied" de Christian Fürchtegott, que Nietzsche imprimió y copió en un cuaderno escolar en 1856 (Hödl 89).

La fuerte influencia de la lírica de Friedrich Güll puede advertirse, en primer lugar, analizando más específicamente el poema "Am Abend", de Nietzsche. Entre los poemas de Güll se encuentra uno titulado "Abendgebet", cuyos versos -"Nun leg auch ich mich hin zur Ruh/ und schließ" die müden Augen zu"4 (Sandmeier 184) - comparten una gran similitud con el poema de Nietzsche: "O schließe sanft mein" Augen zu/ Und gieb mir eine sanfte Ruh"5 (Nietzsche, KGW I/1 226). Temáticas tales como el ruego de protección a Dios ante la oscura y temida noche, agradeciéndole por el día y su protección -que en el presente poema del Nietzsche infantil aparecen en el quinto y sexto verso- son compartidas en ambos poemas. También en el poema "Am Morgen" se advierte una clara influencia de Güll. No solo coincide el título de los poemas, sino también los dos primeros versos, al punto de que Nietzsche parece reproducir los versos de Güll -"Vergangen ist die finstre Nacht,/ Und ich bin fröhlich aufgewacht" (Güll 150)-, cambiando únicamente "fröhlich" por "wieder": "Vergangen ist die finstre Nacht/ Und ich bin wieder aufgewacht"7 (Nietzsche, KGW I/1 225). El tercer verso del poema de Güll continúa: "Was geb' ich denn dir, Gott des Lichts?", expresión que Nietzsche utiliza en el cuarto verso transformando "Gott" por "Herr": "Herr des Lichts".

Un segundo elemento fundamental en la lírica para niños de Güll es la vinculación de la noche con el temor, a través de una oposición entre lo diurno y lo nocturno que se entremezcla con un estado anímico existencial. En la presente antología, esta idea se repite en varios versos, como puede observarse en el poema "Am Abend", donde agradece a Dios que permanezca a su lado para así no temer en los momentos oscuros (Geist 35). Del mismo modo, el poema "Am Abend" de Nietzsche finaliza con un elogio melancólico de Dios y del ruego de protección del yo lírico. Las numerosas Abendgebete en el

\footnotetext{
“Ahora yo también me tumbo a descansar/Y cierro los ojos cansados" [Traducción propia].

“Oh, cierro suavemente mis ojos/ Y permíteme un suave descanso" [Traducción propia].

"La oscura noche ha pasado,/Y he despertado alegremente" [Traducción propia].

"La oscura noche ha pasado,/ Y he despertado de nuevo" [Traducción propia].

“QQué te doy pues, Dios de la Luz?” [Traducción propia].

"Señor de la luz" [Traducción propia].
} 
ambiente evangélico, que sacan a la luz una visión de la noche como momento amenazante, donde relucen problemas existenciales sobre la vulnerabilidad, la finitud, la soledad e incluso la muerte, tienen su origen en la interpretación bíblica de ese momento del día, como periodo ambivalente donde, si bien en algunos pasajes se interpreta de modo positivo -como momento de descanso o en el cual se presentan momentos únicos de experiencias y encuentros únicos con lo divino-, germinan de modo especial los peligros y uno se expone ante sí mismo, ante sentimientos de peligro, soledad y abandono. Esto no solo ocurre para aquel que hipotéticamente se aleja de Dios, sino también, e incluso aún más, para el creyente. Existen numerosos momentos reveladores sobre una connotación negativa de la noche en los Evangelios, como puede ser la respuesta de Jesús a sus discípulos en el pasaje de la muerte de Lázaro, recogida en el Evangelio de San Juan: "Wer bei Tage umhergeht, der stößt sich nicht; denn er sieht das Licht dieser Welt. Wer aber bei Nacht umhergeht, der stößt sich; denn es ist kein Licht in ihm"10 (Lutherbibel, Johannes XI, 10). El uso de la mencionada expresión "Herr des Lichts" en el poema "Am Morgen" de Nietzsche parece tener como trasfondo las palabras que Jesús dirige a los fariseos en el famoso pasaje de la Biblia: "Ich bin das Licht der Welt. Wer mir nachfolgt, der wird nicht wandeln in der Finsternis, sondern wird das Licht des Lebens haben"11 (Lutherbibel, Johannes VIII, 12). Los últimos versos de "Am Abend" -"Erhöhr uns! Drum in Jesu Nahmen/ Sprech ich voll Zuversicht ein Amen"12 (Nietzsche, KGW I/1 226)- están inspirados en una conocida canción del misal protestante con temática pascual, "Jesus meine Zuversicht", la cual se encontraría en el Gesangbuch des Haupt-Vereins für christliche Erbauungsschriften in den Preußischen Staaten, editado en Berlín en 1854 (Hödl 89). Éste cántico se repetirá en diversas ocasiones en los textos y vivencias de Nietzsche en Naumburgo, destacando por ejemplo por ser la canción que sonó durante el entierro de su padre, el 2 de agosto de 1849 (Nietzsche, $K G W I / 1286$ ).

En segundo lugar, Nietzsche dedica otro poema, "Herrschermacht", al poderío del Señor, a través de una dualidad oposicional entre la omnipotencia

10 "El que camina de día no tropieza, porque ve la luz de este mundo. Pero el que camina de noche tropieza, porque no hay luz en él" [Traducción propia].

11 "Yo soy la luz del mundo. El que me sigue no caminará en la oscuridad, sino que tendrá la luz de la vida" [Traducción propia].

12 “Escúchanos! Así pues, en el nombre de Jesús/ Digo con confianza un Amén” [Traducción propia]. 
del creador y la impotencia de señores terrenales y codiciosos que se regocijan en su riqueza y grandes actos. En este poema, Nietzsche reproduce en alemán en los dos últimos versos un término latino característico de la teología protestante que refleja la importante influencia de los himnos y cánticos sagrados en su educación religiosa en Naumburgo: "So sei doch Gott alleine/ Dem Herrn der Herrn, die Ehr"13 (Nietzsche, KGW I/1 223). Soli Deo gloria (en alemán "Gott allein [sei] die Ehre") constituye, junto a sola fide, sola gratia, sola scriptura y solus Christus, los principios teológicos básicos de la Reforma, conformando las denominadas "fünf Solas".

En tercer y último lugar, ocupa un lugar especialmente destacado en la presente antología "Schifferlied", poema que ha sido especialmente discutido por intérpretes como Schmidt, frente al cual se llevará a cabo en el presente artículo un comentario crítico. Considerando este poema como un hito en la lírica de Nietzsche en Naumburgo, Schmidt ve en su autor un alejamiento de las creencias religiosas paternas, envuelto en una pluralidad de figuras retóricas que esconden conflictos existenciales y morales e inserto en una estrategia de ocultación enmascarada ante la madre (Schmidt 341). En este poema destaca la problematización de la felicidad y la desdicha a través de la metáfora del navegante, siendo estos elementos que se encontraban en las tentativas poéticas de Nietzsche en años anteriores, especialmente desde comienzos de 1856. El Nietzsche maduro continuará haciendo uso de la metáfora del viaje en barco, jugando un papel importante en el aforismo 575 de Morgenröthe, "Wir Luft-Schiffahrer des Geistes!", en diversos aforismos de Die Fröhliche Wissenschaft -como el número 124 "Im Horizont des Unendlichen" o el 289 "Nach neuen Meeren"-, así como en las Liedern des Prinzen Vogelfrei, donde recurre frecuentemente a la figura de Colón y a su ciudad natal Génova como símbolos que estimulan al pensador a arrojarse a océanos infinitos e inexplorados del conocimiento, alentado por los versos que cierran el poema "L'infinito" de Leopardi.

Elementos como el barco, el mar, la tormenta, el arrecife o el puerto tienen una larga tradición filosófica y religiosa desde la antigüedad clásica, como puede observarse en la metáfora de Cicerón de la res publica como el barco del Estado y los gobernantes como timoneles ante el carácter intempestivo del mar de la vida. Nietzsche pudo inspirarse para el desarrollo de tales metáforas en las Lieder de Eichendorff, siendo posible encontrar semejanzas 
estilístico-musicales en su poema Der Schiffer. Del mismo modo, la última estrofa de "Schifferlied" de Nietzsche -"Doch läufst du in den Hafen/ Des Schiffes Zielpunkt ein/ Dann wirst du Ruhe finden/ und ewig glücklich sein"14 (Nietzsche, $K G W I / 1225$ )- recuerda especialmente a los tres primeros versos del poema "Im Hafen" de Heinrich Heine, manteniendo los elementos de búsqueda de la felicidad y la vinculación del puerto con la tranquilidad frente al mar turbulento: "Glücklich der Mann, der den Hafen erreicht hat,/ Und hinter sich ließ das Meer und die Stürme,/ Und jetzo warm und ruhig sitzt" ${ }^{\text {"15 }}$ (Heine 227). Además, esta metáfora aparece ya en los Salmos bíblicos, donde la bondad divina reconduce a través del viento a aquellos que, perdidos, se adentran en el mar sufriendo peligros y tormentas, permitiéndoles llegar a puerto seguro (Lutherbibel, Ps CVII, 23-30). Es muy posible que Nietzsche se haya inspirado para este poema en la canción misal "Befiehl du deine Wege", de Paul Gerhardt (Evangelisches Gesangbuch 361-363), la cual tuvo que memorizar y repetir, tal y como se encuentra anotado en su cuaderno de tareas (Nietzsche, $K G W I / 1347)$. Esta Kirchenlied comparte elementos muy similares, como puede observarse en la primera estrofa, en la cual Dios aparece como aquel que dirige y controla los vientos, posibilitando al hombre el encuentro del camino correcto. Además, pueden observarse coincidencias musicales y de contenido más cercanas: mientras que la novena estrofa de "Schifferlied" de Nietzsche comienza con los versos "Ein Ziel doch mußt du haben"16 (Nietzsche, KGW I/1 225), la segunda estrofa de Gerhart versa "Dem Herren mußt du trauen"17 (Evangelisches Gesangbuch 361); y, de nuevo, el cuarto verso de la segunda estrofa de Nietzsche, "Was gut ist oder schlecht"18 (Nietzsche, KGW I/1 224), parece inspirado en el tercer verso de la tercera estrofa de Gerhardt, "was gut sei oder schade"19.

En "Schifferlied", Schmidt ha argumentado que a partir de la cuarta estrofa se encuentra un momento esencial, presentándose la posibilidad de rebasar el seguro camino de Dios arrojándose al inmenso mar, lo que es no obstante

14 "Pero cuando llegues al puerto,/ El destino del barco,/ Entonces encontrarás la paz/ Y serás eternamente feliz" [Traducción propia].

15 "Feliz el hombre que ha llegado al puerto,/ Y ha dejado atrás el mar y las tormentas,/ Y ahora se sienta cálido y tranquilo" [Traducción propia].

16 "Pero debes tener un objetivo" [Traducción propia].

17 "El Señor es en quien debes confiar" [Traducción propia].

18 "Lo que es bueno o malo" [Traducción propia].

19 "Lo que es bueno o perjudicial" [Traducción propia]. 
una posibilidad trágica, puesto que el modo en que podría parecer este libre adentrarse en el mar sería "gracias" a no disponer de mástiles ni velas y a estar incapacitado, por tanto, desde una carencia objetiva, para recibir la voluntad de Dios: sin velas, Dios no podría dirigir el rumbo del hombre; pero sin velas y sin mástil no le quedaría más destino al navegante que naufragar. No obstante, en la estrofa seis se produce, a través de la figura de la isla, un giro problemático-existencial que parece suplir la tragedia de adentrarse en un mar infinito sin las condiciones necesarias para sobrevivir: en medio de la infinitud, podría encontrarse un refugio diferente, lejano y desconocido. Esta isla, además, se trataría en el poema de Nietzsche de un destino concreto donde habita la felicidad: "Hier wohnet nichts als Glück" ${ }^{20}$ (Nietzsche, $K G W$ I/1 224). Sin embargo, los versos siguientes acaban desvelándola como inexistente, como mero producto de la fantasía: "Doch ist's ein schlimm Gebilde/ Der eignen Phantasie"21 (Nietzsche, $K G W$ I/1 225), ante el que hacemos bien resguardándonos: "Doch, hüte dich!"22. Como puede observarse, la advertencia se encuentra dirigida a la segunda persona del singular, siendo interpretada por Schmidt como una recomendación personal a seguir el camino establecido y no desviarse de las normas convencionales de alguien que ha vivido en primera persona tales tentaciones. Schmidt comprende la isla "als erklärtermaßen weltimmanente und rein private Gegenwelt" en oposición al cielo cristiano simbolizado en el poema a través del "puerto seguro". Lo cierto es que el poema finaliza con la llegada a buen puerto como destino natural no desviado por fantasías subjetivas como el único camino posible para alcanzar la felicidad eterna. Schmidt interpreta esta última estrofa como parte de las estrategias de ocultación y enmascaramiento del joven Nietzsche ante la madre después de haber problematizado posibilidades heterodoxas de religiosidad e incluso un incipiente ateísmo, escondiéndose finalmente bajo versos convencionales (340-341).

Si bien las interpretaciones de Schmidt resultan en cierto modo exageradas, defendiendo en el joven Nietzsche una postura claramente atea desde muy tempranos momentos y que parece más bien fruto de una pretensión de

20 “Aquí solo habita la felicidad” [Traducción propia].

21 "Mas es un producto terrible/ De la propia fantasía" [Traducción propia].

22 “Pero ten cuidado!” [Traducción propia].

23 "Como un mundo alternativo declaradamente inmanente y puramente privado" [Traducción propia]. 
proyectar tendencias del Nietzsche tardío en el Nietzsche infantil, es probable, empero, que en este poema se esconda cierta crisis existencial de Nietzsche, replanteándose críticamente problemas teológicos en el contexto de un ambiente familiar religioso. Nietzsche, conocido entre sus compañeros de escuela como el "pequeño pastor" por su actitud sería y pensativa y por su capacidad excepcional de recitar versículos bíblicos (Förster-Nietzsche 28), comenzaría en esta época a albergar pensamientos filosóficos que le permiten fantasear. Para problematizar esta cuestión, el Nietzsche intermedio y maduro ofrece una serie de reflexiones retrospectivas en anotaciones publicadas póstumamente que pueden acercarnos a la posible relación del Nietzsche infantil con la religión. En especial, son relavantes tres fragmentos que aluden a un texto no conservado sobre el origen del mal y el diablo. En 1878, anota Nietzsche: "Als Kind Gott im Glanze gesehn. - Erste philosophische Schrift über die Entstehung des Teufels (Gott denkt sich selbst, dies kann er nur durch Vorstellung seines Gegensatzes)" ${ }^{24}$ ( $\left.K G W I V / 3363\right)$. Unos años más adelante, en 1884, escribe de nuevo que cuando tenía doce años pensó una extraña trinidad conformada por Dios-padre, Dios-hijo y Dios-diablo, con la cual comenzó a filosofar. La conclusión a la que llegó es que para pensarse a sí mismo, Dios tuvo que pensar y crear su opuesto (Nietzsche, $K G W V I I / 2$ 251). A pesar de la discrepancia cronológica de las relaciones retrospectivas del Nietzsche maduro sobre su infancia -en el fragmento póstumo citado de 1884 indica que tales pensamientos sobre el origen del mal surgieron cuando tenía doce años, pero en el prólogo de Zur Genealogie der Moral escribe que fue con trece años (Nietzsche, $K G W V I / 2$ 261)-, parece claro que el hablante quiere situar esta experiencia en el contexto aproximado en el que escribe la presente antología de 1858. Más adelante, en noviembre de 1858, parecen reflejarse pensamientos similares, cuando Nietzsche anota que Dios no es bueno ni malo, sino que está por encima de los conceptos humanos (cit. en Figl 31). En el mencionado prólogo de Zur Genealogie der Moral, Nietzsche volverá a insistir en las experiencias religiosas de su primer escrito filosófico, describiéndola como una edad "wo man 'halb Kinderspiele, halb Gott im Herzen' hat" 25 (KGW VI/2 261).

24 "Cuando niño, Dios contemplado en su esplendor. -Primer escrito filosófico sobre el origen del diablo (Dios se piensa a sí mismo, lo cual solo puede hacer mediante la representación de su opuesto)" [Traducción propia].

25 "Donde se tiene "a medias juegos de niños, a medias a Dios en el corazón"” [Traducción propia]. 
Asumiendo los problemas hermenéuticos que supone considerar las reflexiones retrospectivas de cualquier persona sobre su infancia, esto se recrudece aún más tomando en consideración las estrategias de auto puesta en escena del Nietzsche tardío. Sin embargo, es posible atender a tales anotaciones como una fuente digna de ser considerada, si bien de modo cauteloso. Atendiendo a estas, parecería plausible considerar en el Nietzsche infantil, con doce o trece años, el comienzo de un tipo religiosidad filosófica y heterodoxa, que rebasa los dogmas tradicionales de la tradición protestante, problematizando el origen del mal en Dios desde el pensamiento de esa "extraña" trinidad, y, sin embargo, inserto aún en el cristianismo. Este alejamiento de la tradición religiosa iría culminando en sus años de juventud, especialmente durante su estancia en Pforta. El argumento principal de esta hipótesis sería un escrito de 1879, donde Nietzsche, de nuevo retrospectivamente, hablará de sí mismo en la época del internado como ateo ( $K G W I V / 3466)$.

Cabe advertir finalmente, para defender contra Schmidt la tesis de un Nietzsche aún cristiano, en Naumburgo, que también dentro de la "creencia" es posible la duda y la desesperanza, sin implicar necesariamente una posición superadora de la religión. Esto puede observarse, por ejemplo, volviendo a la mencionada canción misal "Befiehl du deine Wege", que ha podido inspirar el poema "Schifferlied" de Nietzsche. En la canción de Gerhardt, la sexta estrofa manifiesta una llamada a la esperanza ante las dificultades: "Hoff, $\mathrm{O}$ du arme Seele/ Hoff und sei unverzagt!"26, compartiendo la experiencia de la angustia y el sentimiento de flaqueza, así como versos intermedios de posibles peligros y desesperanza y finalizando, como el poema de Nietzsche, con la felicidad que alcanza el creyente. Esta advertencia podría servir de contraargumento a las interpretaciones de Schmidt, posibilitando una interpretación heterodoxa, quizás filosófica y más subjetiva de la religión que la asunción de una posición estrictamente atea. Del mismo modo, la ligazón de la noche con un tipo de experiencia personal-existencial impía o de alejamiento de la religión en los poemas "Am Abend" y "Am Morgen", expresan en los últimos versos no tanto un sentimiento desesperado ante un ateísmo incipiente, sino más bien expresiones típicas del ambiente pastoral en el que creció, los escritos bíblicos y los Gesangbuch evangélicos. El Nietzsche infantil estaba inmerso en el ambiente cultural protestante, era un conocedor excelente de la Biblia de Lutero y es posible que sus modos de 
filosofar comenzaran siendo en un principio una extensión y problematización de los principios de la cristiandad -en cierta medida "desde dentro"-, que lo condujeron a una religiosidad que excedía los dogmas tradicionales. Figl interpreta de un modo parecido esta experiencia infantil, viendo en ella elementos que suscitan una religiosidad propia e individual vivida de modo intenso en estos años infantiles y que trascienden los dogmas rígidos luteranos y todo supuesto conformismo religioso, mediante una superación de las oposiciones en el pensar occidental (28-29). Montinari, en tanto, ve en el Nietzsche infantil, en la época previa a su ingreso en Pforta, una temprana tendencia a la Freigeisterei, como inicios del pensamiento crítico filosófico, que no obstante era compatible con su religiosidad (37).

\section{LÍRICA DE LA NATURALEZA COMO EXPRESIÓN ROMÁNTICA}

Asimismo, en las producciones líricas del Nietzsche infantil en Naumburgo destacan numerosas tentativas sobre la naturaleza, donde se dejan ver influencias de autores románticos, si bien la división entre "lírica religiosa" y "lírica de la naturaleza" será más bien un patrón regulativo ficcional, que nos servirá para distinguir determinadas motivaciones generales que se entrecruzan: la naturaleza es tematizada en la mayoría de los casos como fruto de la creación divina y entremezclada a menudo con problemas existenciales. En la antología de 1858, este rebasamiento de fronteras puede observarse claramente en el ciclo poético Der Winter, en el cual predomina una lírica romántica e idílica de la naturaleza desde un tono afectivo y melancólico, a través de una personificación de las estaciones que enfatiza un trasfondo religioso, teniendo como fuentes de inspiración numerosos versos y pasajes bíblicos de los Salmos y Evangelios, así como una tematización de la vida y la muerte desde una perspectiva dualista cristiana. Por un lado, la naturaleza y la religión se muestran como vías de escape, como dimensiones de búsqueda de consuelo ante un estado afectivo existencial dominado por sentimientos de soledad. Por otro lado, sin embargo, se manifiestan momentos dichosos de vida en familia y la celebración de fiestas religiosas que parecen mostrar, paradójicamente, una feliz integración social.

Der Winter se caracteriza por ser un conjunto poético muy elaborado, con una pluralidad de temáticas y motivos heterogéneos y dividido, además, en partes amplias y estructuradas con diferente número de versos y estrofas. En la antología ocupa el segundo lugar y refleja cómo Nietzsche iba siendo capaz 
de crear composiciones y ciclos tan abarcadores. En términos generales, se pueden destacar tres partes esenciales: las primeras anuncian el advenimiento del invierno desde una perspectiva efímera de lo real, la tercera y cuarta parte giran en torno a la fiesta de la Navidad y la quinta y última parte expone, dichosa, el advenimiento esperanzado de la primavera.

En esos años, las tentativas líricas de la naturaleza dejan ver una fuerte influencia de autores románticos en Nietzsche: el canto a una naturaleza en devenir, pasajera y efímera a través del cambio de las estaciones va acompañado de una atribución de sentimientos intensos a las cosas naturales. Al igual que en poetas como Eichendorff o Heine, es habitual el recurso de naturalismos como medio de expresar estados anímicos, pretendiendo reproducirlos en el alma del lector, por ejemplo, al hacer soñar o dormir a las cosas. En la primera estrofa de la segunda parte, Nietzsche utiliza expresiones como "im freien Tempel der Natur" ${ }^{27}$ (KGW I/1 217), que puede encontrarse en la lírica de Rückert: "Ihr Waffen ist Gebet, ihr Ruhm Gesang und Psalmen/ Im Tempel der Natur gesungen unter Palmen"28 (106). La naturaleza es además un recurso frecuente en el que el individuo solitario encuentra consuelo, algo también presente en poemas como "Die Einsame", de Eichendorff. La naturaleza como refugio del solitario es un tema predominante en la poesía del Nietzsche infantil y juvenil. En la autobiografía de octubre de 1858 Nietzsche escribe cómo desde pequeño buscaba la soledad, encontrándose mejor allí donde no podía ser molestado por nadie. En "el templo libre de la naturaleza", escribe, repitiendo la expresión romántica utilizada en Der Winter, encontró al amigo más verdadero, pudiendo fantasear y escapar de las experiencias dolorosas ( $K G W I / 1288)$. La inspiración bíblica otra vez es importante, en especial en dos momentos. En primer lugar, aparece al final de la tercera estrofa la figura del ángel y de Dios como "Schutz und Schirm", metáfora que en la biblia de Lutero aparece en diversos pasajes de los Salmos, o la metáfora de Dios como protección, como escudo (Schutz): "Meine Stärke, zu dir will ich mich halten; denn Gott ist mein Schutz"29 (Lutherbibel, Ps LIX, 10) o "Du bist mein Schutz und mein Schild; ich hoffe auf dein Wort" 30

27 "En el templo libre de la naturaleza" [Traducción propia].

28 "Sus armas son la oración, su gloria el cántico y los salmos/ Cantados en el templo de la naturaleza bajo las palmeras" [Traducción propia].

29 "Mi fuerza, a ti quiero acogerme, porque Dios es mi protección" [Traducción propia].

30 “Tú eres mi protección y mi escudo; confío en tu palabra" [Traducción propia]. 
(Lutherbibel, Ps CXIX, 114). En segundo lugar, la cuarta estrofa del poema de Nietzsche -y especialmente los dos últimos versos, "Wer sein Vertraun auf ihn legt/ Sein Haus auf festen Fels wird bauen"31 - alude claramente al Evangelio según Mateo:

Darum, wer diese meine Rede hört und tut sie, der gleicht einem klugen Mann, der sein Haus auf Fels baute. Als nun ein Platzregen fiel und die Wasser kamen und die Winde wehten und stießen an das Haus, fiel es doch nicht ein; denn es war auf Fels gegründet ${ }^{32}$ (Lutherbibel, Matthäus VII, 24-25).

Respecto a las influencias estilísticas más concretas del poema, Peter Bloch plantea la posibilidad de que Nietzsche haya tenido como base para la composición de Der Winter el poema de Paul Gerhardts, "Geh aus, mein Herz, und suche Freud" (Bloch 628). Este poema suscita una discusión sobre la posición religiosa de Nietzsche en Naumburgo. Schmidt interpreta esta composición como una muestra de que Nietzsche se encuentra de camino hacia una devoción o religión de la naturaleza, unido a un interés histórico y literario por los griegos que se ejemplifica en expresiones como "en el templo libre de la naturaleza" o en la referencia a una "tranquilidad sagrada", oponiendo la metáfora del templo de la naturaleza, que se presentaría como libre y sagrado desde sí, frente a la ausencia de libertad en los templos cerrados eclesiásticos (Schmidt 315-322). Desde 1854, las divinidades griegas serían capaces de encarnar mundos alternativos al cristiano paternal que le permiten a Nietzsche explorar nuevas dimensiones de libertad (Schmidt 791-792). Estas tentativas irían de la mano de motivos panteístas expresados en la naturaleza, viendo en ella una especie de poder superior, como puede observarse en la metáfora del templo libre de la naturaleza. Esta interpretación ha ocasionado un fructífero debate que pone en cuestión una asunción tan directa como la que plantea Schmidt y advierte la necesidad de cautela ante tales lecturas, evitando extrapolar tentativas posteriores a momentos anteriores. Ciertamente, en Pforta serán múltiples los poemas de Nietzsche que parecen

31 "El que confía en él/ Construirá su casa sobre una roca firme" [Traducción propia].

32 "Por tanto, el que oiga estas palabras mías y las ponga en práctica, será como un hombre prudente que construyó su casa sobre la roca. Cuando cayó la lluvia, y vinieron las aguas, y soplaron los vientos, y golpearon aquella casa, no cayó, porque estaba fundada sobre la roca" [Traducción propia]. 
apuntar hacia una experiencia panteísta o una religión de la naturaleza. Sin embargo, esto no parece tan claro aún en su periodo en Naumburgo. En este sentido, Joergen Kjaer critica fuertemente la interpretación de Schmidt defendiendo, contrariamente, una lírica fuertemente cristiana inserta en la tradición luterana bajo la influencia de Schiller (357). Pues, en contraposición a los poetas modernos, para Schiller los griegos no ejercían una diferencia tajante entre el mundo de la naturaleza y el mundo de los humanos, entre lo natural y lo divino, puesto que en la experiencia griega de la religiosidad estas esferas se atravesaban unas a otras de tal modo que lo social, lo natural, lo externo y lo interno formaban parte de movimientos continuos de ida y venida y rebasamiento de cualquier delimitación moderna. En este sentido, la naturaleza no podría ser un refugio más allá de lo social, puesto que tal distinción se presentaría radicalmente anulada. La función de los griegos en el Nietzsche infantil es, bajo la perspectiva de Kjaer, más bien un campo de experimentación "cristiana”, en el sentido de que le sirve para tematizar una relación oposicional entre Jesús, Yahveh y Júpiter. El Dios que alaba Nietzsche en Naumburgo sería, para Kjaer, no el Yahveh destructor y autoritario del Antiguo Testamento, sino más bien un Dios cercano, redentor, que encarna en la tradición familiar protestante la cosmovisión materna de Jesús. El Júpiter de los poemas tempranos de Nietzsche sería un modo de referirse a ese Jesús que ama, en contraposición al despótico Zeus, utilizado como alusión a Yahveh, siendo por tanto este recurso más bien un modo de valerse del mundo antiguo para expresar de modo más cercano ideas cristianas. Cercano a la posición de Kjaer, Hödl defiende que la interpretación de un posible uso de las divinidades griegas que rebase lo cristiano no se sustenta por el hecho de que, en el contexto pruso-luterano en el que crece Nietzsche, los griegos son comprendidos insertos en el marco de una cultura judeocristiana, tanto en la vida privada y las discusiones con amigos, así como en la escuela (93-94).

Cabría además resaltar, contra la preponderancia de poemas griegos, que en la presente antología no se encuentra ninguna metáfora o uso de dioses helénicos, si bien estos constituyen en el Nietzsche infantil un campo de experimentación esencial en múltiples tentativas líricas de años anteriores y posteriores. Resulta especialmente tentador asumir las posturas de Schmidt y considerar un Nietzsche en Naumburgo panteísta o alejado del cristianismo, debido a que los escritos intermedios y tardíos parecerían hablar a favor de tal posición. En los años venideros es posible encontrar múltiples poemas que parecen expresar posiciones panteístas, entre las que podemos resaltar algunos versos que escribirá un año después: "O Sonne o hab mit uns armen 
Erbarmen / Laß uns nicht durch deine Allmacht vergehen" ${ }^{33}$ (Nietzsche, $K G W$ $I / 264)$, donde el sol es tratado como un ser vivo. En la presente antología se ha advertido además la existencia de una lírica de la naturaleza que expresa sentimientos y la capacidad de experienciar posibles mundos subjetivos en plantas y árboles a través del lamento. Sin embargo, en la mayoría de sus escritos de Naumburgo esas aparentes inclinaciones panteístas finalizan con elogios cristianos a Dios que traen a la luz una experiencia de la dicha que se corresponde con una bienaventuranza trascendente.

El segundo ejemplo de este rebasamiento de fronteras lo encontramos en "Ein Gewitter", poema de una sola estrofa de cuarenta y cuatro versos que pone de relieve el poder destructor de las tormentas que van consumiendo, entre llamas, todo aquello que encuentran a su paso, repitiendo hasta cinco veces el grito "compasión" (Erbarmen) mostrando un especial dramatismo expresivo. Las tormentas en la poesía infantil de Nietzsche juegan con la dualidad de la destrucción y la fascinación, acompañada de una personificación del fenómeno atmosférico que encuentra múltiples resonancias entre sus lecturas románticas. Puede destacarse por ejemplo el poema "Gewitter", de Nikolaus Lenau, en el que una tormenta abrupta irrumpe una previa tranquilidad y tiene como consecuencia el advenimiento del caos y el terror, poniendo de manifiesto su fuerza destructiva (Lenau 508-509). Nietzsche dedicará diversas tentativas a este fenómeno, pudiendo observar en el periodo previo a Pforta otro poema en la antología que en 1856 regala a su madre por su cumpleaños, titulado "N. 8 . Gewitter" (KGW I/1 122). Además, las tormentas serán recursos que, junto a la fuerza extraordinaria de lo natural, son interpretados como manifestaciones religiosas de una experiencia ambigua de admiración y temor, como puede observarse de nuevo en su autobiografía de 1858, donde destaca, desde una experiencia subjetiva, lo bello y hermoso de la impresión que le produce la tormenta, señalando que los rayos y truenos aumentan su respeto y veneración hacia Dios (Nietzsche, $K G W I / 1288$ ). Es curioso observar cómo en su primera autobiografía diversas muertes familiares van precedidas de la experiencia de una tranquilidad en la que irrumpen nubes negras y relámpagos, anotando tal fenómeno tanto cuando anuncia la muerte de su padre como la de su tía Auguste (KGW I/1 285 y KGWI/1 299).

\footnotetext{
33 "Oh, sol, oh, ten misericordia de estos pobres/ No permitas que perezcamos por tu omnipotencia” [Traducción propia].
} 


\section{LÍRICA POLÍTICA Y CANTOS PATRIÓTICOS ENTRE EL VORMÄRZ Y EL BIEDERMEIER}

Si bien en esta antología solo aparece un poema explícitamente político entre los diez que la conforman, atender a esta dimensión será fundamental para comprender el contexto y desarrollo de las tendencias infantiles y juveniles de Nietzsche. El poema "An Theodor Körner", de tan solo tres estrofas de cuatro versos cada una, está impregnado de un fuerte contenido patriótico, tratándose de una oda al "poeta político" Theodor Körner, caído con 22 años (1791-1813) cuando formaba parte del batallón voluntario Lützowsche Freikorps del ejército prusiano en las "Guerras de liberación" (Freiheitskriege) contra Napoleón. En este poema, Nietzsche resalta el heroísmo del joven héroe que entrega su vida combatiendo a los franceses. Es destacable cómo el elogio no se da a partir de una categoría anónima o colectiva, como puede ser el pueblo, sino desde la de un individuo, ensalzando a un héroe concreto. Los movimientos burgueses emergentes, encarnados en los poetas leídos por el joven Nietzsche, se insertan en esa tendencia liberal que rescata la libertad política y del individuo frente a los príncipes, que tienden a ser libres de coacciones externas. Esto se ve reflejado, por ejemplo, en el caso de Lenau, quien, a pesar de su origen noble, decidió, en un impulso crítico contra la clasificación de los individuos en función de su origen, modificar su nombre original.

El poema expresa la idea del sacrificio por principios superiores como una entrega digna de elogio. La libertad de los alemanes frente a los invasores se presenta, en este caso, como un motivo por el que es digno morir a pesar de lo sangriento de la contienda: "Für die Freiheit littest du den Tod/ Doch es tagte schon das blutge Morgenroth" ${ }^{34}$ (Nietzsche, KGW I/1 222). Estos versos, además, parecen reproducir una simbología utilizada por el mismo poeta caído en sus versos, concretamente atendiendo a los penúltimos versos de "Lied zur feierlichen Einsegnung des preußischen Freikorps", de Körner, cantado el 28 de mayo de 1813 en la iglesia de Rochau, en Schlesien: "Und führt uns, wär's auch durch den Tod/ Zu seiner Freiheit Morgenrot”" ${ }^{35}$ (Körner

\footnotetext{
34 "Por la libertad sufriste la muerte/ Pero el sangriento amanecer ya estaba despuntando" [Traducción propia].

35 "Y llévanos, aunque sea a través de la muerte/ Al amanecer de su libertad" [Traducción propia].
} 
11). Tanto el poema de Nietzsche como el de Körner comparten las ideas de la muerte y libertad, así como la metáfora de la aurora. Es interesante notar que los elementos mortuorios, como la tumba, el foso o la muerte, no son tematizados desde un estado afectivo existencialista o melancólico, sino a través de la voluntad férrea, temeraria y heroica del joven héroe, incluso dichosa, que contrasta con otros muchos poemas en los que predominan tales estados sombríos. La dicha, sin embargo, es celebrada como bienaventuranza celestial y trascendente, cuando, tras su muerte, el héroe caído se encuentra ante el trono supremo, ante Dios, entre gritos de júbilo por la venidera satisfacción divina de sus deseos: "Dein höchster Wusch auf Erden/ Wird noch schöner dort erfüllt werden/ Wo du jauchzest vor des Höchsten Throne" ${ }^{" 36}$ (Nietzsche, $K G W I / 1222$ ).

Theodor Körner fue, como se ha advertido en la introducción, una lectura muy estimulante para el Nietzsche infantil. Atendiendo a Hödl, nada menos que el primer poema conservado, "Dort auf jener Felsenspitze" (1854) -si hacemos excepción de los Festtagsgedichte y del material escolar-, está inspirado en los versos de "Vom Dreikreuzen-Berge" de Körner (Hödl 109). En el borrador conservado póstumamente que sirvió de material esquemático para su primera autobiografía - escrita a finales de 1858-, se encuentra de nuevo la figura del poeta político, bajo el apartado "pensamientos", titulado "Ueber Körner. Gedichte" (Nietzsche, KGW I/1 279). La pasión del joven Nietzsche por Körner irá intensificándose en los años venideros, donde llevará a cabo diversas actividades de investigación y divulgación científica sobre su persona, como puede verse en el discurso sobre los "poetas políticos" que, ya en su época de estudiante en Bonn, llevará a cabo como miembro de la asociación de estudiantes Frankonia, en 1865. A pesar de no disponer del discurso escrito, se ha conservado un esquema que desarrolló como guía y en el que destaca la figura de Körner. A nivel de contenido político, es especialmente interesante observar los puntos esenciales en los que se divide este esquema. En primer lugar, dedica un punto hacia el sentimiento del sí mismo alemán contra lo no-alemán (das Undeutsche); en segundo lugar, lo popular (volksthümlich) contra aquellos que lo oprimen; en tercer lugar, lo alemán liberal contra el absolutismo (Nietzsche, KGW I/4 60-61). Estas tendencias del joven Nietzsche resultan extrañas para los lectores de

36 "Tu más alto deseo en la tierra/ Se cumplirá aún más hermosamente allí/ Donde te regocijas ante el más alto trono" [Traducción propia]. 
las obras más tardías de Nietzsche, en las cuales su filosofía se caracteriza por una tendencia europeísta de superación de los pequeños nacionalismos emergentes y la oposición frontal a las políticas expansionistas de Bismarck, insertándose en las tendencias cosmopolitas que tienen sus raíces en el cínico Diógenes de Sinope. Sin embargo, el Nietzsche infantil y juvenil se encuentra aún inmerso en las ensoñaciones nacionalistas, tal y como se puede observar en las numerosas poesías, anotaciones, ensayos y correspondencia de estos años.

Resulta también llamativo el tercer punto del esquema borrador mencionado para su conferencia juvenil en Bonn, apelando a lo alemán liberal como apuesta política. Lo cierto es que el joven Nietzsche se inclinará favorablemente hacia la instauración de una república alemana, entusiasmándose con una unificación que trasciende las posiciones conservadoras de la Restauración y acercándose a las ideas propias del Vormärz: libertad, unidad y república (Freiheit, Einheit, Republik) y una predominancia de posiciones políticas patrióticas que recuerdan a la lírica de Byron o Hölderlin, como advierte Ottmann (12). La pasión juvenil por tales ideas envuelve a Nietzsche en esta época hasta tal punto que en una carta a su amigo Raimund Granier se lamenta explícitamente de no haber nacido veinte o treinta años antes, justo en aquella época de hombres que podían entenderlo ( $K G B I / 283)$, coincidiendo precisamente con la época más efervescente de ese movimiento. Heine o Platen serán autores a los que Nietzsche volverá una y otra vez, a los cuales autores como el germanista Farese incluye entre la lírica del Vormärz (227).

Volviendo a las tentativas lírico-políticas del Nietzsche infantil, es claramente visible que tienen como suelo nutricio el ascendente nacionalismo alemán. En la primera autobiografía, que escribe en 1858, justo antes de ingresar en Pforta, Nietzsche hace referencias a la vecina ciudad de Lützen, de la cual destaca su importancia histórica siendo escenario de grandes batallas que regaron sus tierras con la sangre de distintos pueblos europeos. Además, resalta los distintos memoriales de la ciudad, que recuerdan la gloria de los héroes caídos (Nietzsche $K G W I / 1$ 284). Entre otros elementos, destaca su vecindad con Poserna, ciudad que se encuentra a tan solo una hora de Lützen y que es la ciudad que vio nacer a Johann Gottfried Seume, de quien destaca no solo su lírica sino también su patriotismo. Un año después, ya en Pforta, llevará a cabo una nueva tentativa lírica con un fuerte tono combativo, llamando a defender la patria y liberarla de las cadenas (Nietzsche, KGW I/2 60-61).

Atendiendo al ambiente estrictamente tradicional y evangélico en el que creció Nietzsche, ciertamente resultan sorprendentes estas tentativas, que ponen de relieve conflictos sociales y que parecen tan distanciadas del 
conservadurismo del Biedermeier, caracterizado por el alejamiento de las convulsiones y revueltas, en una reivindicación apolítica de la comodidad y el calor del hogar. Mientras que estudiosos como Ottmann han destacado más bien el acercamiento de la lírica de Nietzsche en estos años a la política del Vormärz (12), otros como Kjaer han insistido en la caracterización del ambiente cultural en Naumburgo como una clara infancia cristiana típica del Biedermeier (355-357). Ciertamente, en esta antología hay poemas que podrían categorizarse dentro de esta corriente, como es el ejemplo de los mencionados "Abendgebete" y "Morgengebete", así como el ciclo poético Der Winter, en el cual dedica estrofas a una naturaleza idílica, resaltando el carácter transitorio, la comodidad del hogar y las tradiciones religiosas como la Navidad, además de los muchos poemas indicados, cuya temática principal es el amor maternal con agradecimientos frecuentes del yo lírico a Dios. Saludar el advenimiento de una primavera personalizada, como finaliza Der Winter, es también un recurso frecuente en la lírica conservadora de Eduard Mörike. La hermana de Nietzsche escribe cómo el ambiente político familiar que dominaba en los primeros años de su infancia estaba especialmente marcado por la aflicción del padre debido a los acontecimientos de la revolución de 1848, ocurrida cuatro años después del nacimiento de Nietzsche. Carl Ludwig Nietzsche era un conservador firmemente monárquico, que incluso bautizó a su hijo, nacido el mismo día que el rey de Prusia, con su nombre para honrarlo: Friedrich Wilhelm. Tras la oleada revolucionaria, el padre prohibió hablar de política o sublevaciones en casa (Förster-Nietzsche 18). Después de la muerte del padre y el consiguiente traslado de la familia a Naumburgo, se respiraba también en la nueva ciudad un ambiente político estrictamente conservador, cristiano y monárquico.

Sin embargo, los movimientos burgueses, conservadores y liberales emergentes parecían cohabitar incluso dentro de ambientes tan tradicionales. Lecturas como Heine o Körner, íconos del Vormärz, al lado de Friedrich Güll, ejemplo paradigmático de la lírica infantil Biedermeier, son prueba de ello. Un nuevo ejemplo de esta convivencia de tendencias contradictorias es la admiración que unos meses después, en la autobiografía de 1848, Nietzsche mostrará hacia a "su rey" por su visita a Naumburgo en 1854, a pesar de las muestras de fervor unificador alemán contra el conservadurismo. Nietzsche refleja además cómo la tranquilidad que se vivía en esa época en Röcken contrastaba con las convulsiones y revueltas que se producían en Europa ( $K G W$ I/1 284). En medio de tales anotaciones, escribe Nietzsche cómo le impresionó ver el movimiento y traslado de carros de combate, así como la rapidez con 
la que se reprimió la lucha revolucionaria en París que fue secundada por la mayoría de las ciudades prusianas, donde se mantuvo vivo largo tiempo el anhelo de una república alemana ( $K G W I / 1284)$. Así, Nietzsche parecía ser consciente de las transformaciones sociales que su época encarnaba. Un posible argumento explicativo de esta paradoja podría ser la mencionada influencia de su abuelo, cuyas posiciones más progresistas y humanistas trascendían en cierto modo el conservadurismo que se respiraba en la educación paterna, siendo el origen de estímulos heterodoxos. No obstante, lo cierto es que esas épocas convulsas, que vivió el joven Nietzsche en la Prusia de comienzos de la segunda mitad del siglo XIX, fueron ricas en contradicciones y los patrones que pretenden apresar la realidad con distinciones claras y distintas suelen no acertar y obviar las complejidades de la historia viva: ambas tradiciones que lideraron los conflictos sociales prusianos entre 1815 y 1848 pueden, como se constata de facto en la familia Nietzsche, convivir de algún modo a comienzos de la segunda mitad del siglo XIX.

\section{CONCLUSIONES}

El análisis realizado constata, en primer lugar, la intensidad y lo prolífico de las creaciones líricas de Nietzsche en su edad más temprana, mostrando la multiplicidad de perspectivas de las tentativas poéticas en su último año en Naumburgo, complementándolo con indicaciones o extensiones de las transformaciones venideras en los primeros años de Pforta. Esta diversidad de puntos de vista ha mostrado, además, la riqueza de las lecturas que Nietzsche llevaba a cabo con tan solo trece años, viéndose influenciado por numerosos autores románticos, escritos bíblicos y prácticas del servicio religioso. En estos poemas, además, se han puesto de relieve tanto reflexiones existenciales como pensamientos sobre la naturaleza y la religión, así como las vivencias religiosas o políticas que se respiraban en el ambiente familiar, aportando importante material para adentrarnos en los esfuerzos de superación que el Nietzsche intermedio y maduro irá encarnando para dialogar críticamente con las fuertes raíces luteranas en las que creció. Haber nacido en el contexto de una casa parroquial protestante le otorgó sin duda una experiencia muy peculiar y fructífera, a partir de la cual irá edificando sus perspectivas.

En segundo lugar, el análisis se ha llevado a cabo desde una pretendida visión amplia, es decir, a partir de unos presupuestos que abrieran lo máximo posible sus experiencias desde una pluralidad de voces, sin dejarse llevar 
por los cánones dominantes en la interpretación tradicional de sus vivencias infantiles, en los que, en muchos casos, prepondera de modo unilateral un rechazo a sus progenitores y a sus creencias religiosas o la experiencia de soledad como estado anímico quasi absoluto. Respecto a la primera cuestión, se ha mostrado cómo Nietzsche en estos años parecía, contrariamente, estar inmerso en una actitud muy religiosa, si bien posiblemente de modo heterodoxo, atendiendo desde sus primeras tentativas filosóficas al origen del mal. Además, se ha advertido la importante función de su abuelo, David Ernst Oehler, en su educación, que abrió a Nietzsche a pensamientos humanistas, a una visión más progresista, a la vez que amplió sus conocimientos sobre poesía y literatura. Respecto a la experiencia de la soledad, si bien se han mostrado momentos y tentativas que reflejan indiscutiblemente un estado anímico melancólico y momentos en los que prepondera la soledad, así como diversas reivindicaciones explícitas de tal fenómeno, esta antología es útil para complejizar y poner en cuestión toda tesis unilateral que haga de esa experiencia un absoluto que oculte experiencias afectivas diferentes. Para ello, se han resaltado afectos más dichosos y empáticos del yo lírico e incluso sentimientos de amor piadoso hacia sus familiares o hacia Dios y, como se ha mostrado, es posible incluso ver momentos de dicha concomitantes a impulsos patrióticos y combativos. Estas advertencias buscan un punto de vista múltiple que sea capaz de visibilizar la pluralidad de voces y diversos pathos afectivos "contradictorios" que cohabitan en la poesía de Nietzsche en Naumburgo.

En tercer lugar, se ha sacado a la luz la perspectiva política de su lírica, reflejando cómo los anhelos e intereses del Nietzsche infantil y juvenil se abrían a un horizonte de participación social, introduciéndose en un movimiento transformador naciente y saludando en los años venideros la unificación y la república alemana. Las diversas tentativas líricas mostradas, así como las actividades científicas de investigación que llevaría a cabo en Naumburgo, Pforta e incluso en Bonn, son prueba del rebasamiento de una poesía dedicada exclusivamente a una exaltación apolítica de la naturaleza.

En cuarto y último lugar, se ha procurado conscientemente evitar una subsunción y proyección de las así llamadas "doctrinas" del Nietzsche tardío, como puede ser la voluntad de poder o el eterno retorno, evitando reducir la autenticidad existencial de estos primeros años y su contexto vital a una ficticia precuela directa de sus escritos tardíos, que fuera accesible al lector y le permitiera llevar a cabo movimientos de ida y vuelta sin cometer abusos hermenéuticos. Para ello, ha sido fundamental atenerse a las fuentes a las 
que el Nietzsche infantil, ávido lector, tenía acceso, tanto en el ambiente familiar como en el escolar. Ser susceptibles a la pluralidad de voces que resuenan en el Nietzsche infantil e intentar comprender sus intereses más tempranos desde su contexto permite complejizar y enriquecer el modo en que nos enfrentamos a sus escritos tardíos.

\section{BIBLIOGRAFÍA}

Bloch, Peter André. “Nietzsches 'Weinachten' und 'Neujahr'. Feiertage des jungen

Nietzsche im Naumburger Familien und Freundeskreis. Der Mensch - sein eigenes Experiment?

Beatrix Vogel (ed.), München, Allitera Verlag, 2008. Evangelisches Gesangbuch. Karlsruhe,

Evangelischer Presserverband für Baden, 1996.

FARESE, GiusepPe. "Lyrik des Vormärz" Deutsche Literatur. Eine Sozialgeschichte. Vormärz:

Biedermeier, Junges Deutschland, Demokraten, 1815-1848, Hamburg: Rowohlt Taschenbuch

Verlag GmbH 1980, pp. 227-245.

Figl, Johann. Geburtstagsfeier und Totenkult. Zur Religiosität des Kindes Nietzsche,

Nietzscheforschung 2. Berlin, Akademie Verla, 1995, pp. 21-34.

Förster-Nietzsche, Elisabeth. Der junge Nietzsche. Leipzig, Alfred Kröner Verlag, 1912.

Geist, Joseph Anton. Sprachübungen für deutsche Schulen. Für die Unterklassen. Kempten, Kösel, 1843.

GüLl, Friedrich. Kinderheimath in Bildern und Liedern. Stuttgart, S.G. Liesching, 1836.

Grätz, Katharina y Sebastian Kaufmann. Nietzsche als Dichter. Lyrik-Poetologie-Rezeption.

Berlin / Boston, Walter de Gruyter, 2017.

Heine, HeinRICH. Sämtliche Gedichte. Bernd Kortländer (coord.), Stuttgart, Philipp Reclam, 1997.

Hödl, Hans Gerald: “Jugendschriften (1852-1869)”. Handbuch Nietzsche. Leben-WerkWirkung, Ottmann, Henning. Stuttgart-Weimer, J.B. Metzler, 2000.

KJAer, Joergen. Nietzsches Naumburger Texte: synkretistische mythopoetische Theodizee oder antichristliche Theodizeekritik?. Nietzscheforschung 2. Berlin, Akademie Verlag, 1995, pp. 341-369.

Körner, Theodor: Leyer und Schwerdt. F. M. Kircheisen (ed.), Berlin, Morawe \& Scheffelt Verlag, 1913.

Lenau, Nikolaus. Sämtliche Werke und Briefe in zwei Bänden. Erster Band, Gedichte und Versepen, Insel Verlag, 1985.

Lutherbibel. Die Bibel nach Martin Luthers Übersetzung. Deutsche Bibelgesellschaft. Deutschland, Evangelische Kirche, 2017.

Montinari, Mazzino. Nietzsche lesen. Berlin, Nueva York, Walter de Gruyter, 1982.

NietZsche, Friedrich. Gedichte und Sprüche. Leipzig, Naumann, 1908. 
Nietzsche Werke. Kritische Gesamtausgabe, Johann Figl (ed.), Berlin, Walter de Gruyter, 1995 (KGW I/1).

Nietzsche Werke. Kritische Gesamtausgabe, Johann Figl (ed.), Berlin, Walter de Gruyter, 2000 (KGW, I, 4).

Nietzsche Werke. Kritische Gesamtausgabe, G. Colli y M. Montinari (eds). Berlin, Walter de Gruyter, 1967 (KGW IV/1).

Nietzsche Werke. Kritische Gesamtausgabe, G. Colli y M. Montinari (eds.),Berlin, Walter de Gruyter, 1967 (KGW IV/3).

Nietzsche Werke. Kritische Gesamtausgabe, G. Colli y M. Montinari (eds.),Berlin, Walter de Gruyter, 1968 (KGW VI/2).

Nietzsche Werke. Kritische Gesamtausgabe, G. Colli y M. Montinari (eds.), Berlin, Walter de Gruyter, 1974 (KGW VII/2).

Sämtliche Briefe. Kritische Studienausgabe in 8 Bänden, G. Colli y M. Montinari (eds.), Deutscher Taschenbuch Verlag de Gruyter: 1986 (KGB, I/2).

Ottmann, Henning. Philosophie und Politik bei Nietzsche, Monographien und Texte zur

Nietzsche-Forschung, Berlin, Nueva York, Walter de Gruyter, 1999.

RÜCKert, Friedrich. Die Weisheit des Brahmanen, ein Lehrgedicht in Bruchstücken. Bd. 1. Leipzig, Weidmann, 1836.

SANDMEIER, M. Methodisch praktische Anleitung zur Ertheilung eines geist- und gemüthbildenden Unterrichts der Naturkunde in Volksschulen, Baden: J. Tuchschmid, 1848.

Schmidt, Hermann Josef. Nietzsche absconditus oder Spurenlesen bei Nietzsche. Kindheit. Teil I / II Zugänge und Entwicklung, Berlin-Aschaffenburg, IBDK, 1991.

Schlechta, Karl. Nietzsche Chronik: Daten zu Leben und Werk, Hanser, München, Wien, Hanser, 1975. 
